Mills, E. L., Debets-Ossenkopp, Y., Verbrugh, H. A. and Verhoef, J. 1981. Initiation of the respiratory burst of human neutrophils by influenza virus. - Infect. Immun. 32: 1200-1205.

STUART-HARRIS, C. H. 1979. The influenza viruses and the human respiratory tract. - Rev. Infect. Dis. 1: $592-599$.

Weiss, S. J. and LoBuglio, A. F. 1980. An oxygen-dependent mechanism of neutrophil-mediated cytotoxicity. - Blood 55: 1020-1024.

\title{
Adhesion of coagulase-negative staphylococci with different surface characteristics onto a hydrophobic biomaterial
}

\author{
A. H. HogT ${ }^{1}$, J. DANKERT ${ }^{2}$ and J. FeIJEN ${ }^{1}$ \\ ${ }^{1}$ Department of Chemical Technology, Section of Biomaterials, Twente University of Technology, \\ P.O. Box 217, 7500 AE Enschede, The Netherlands \\ ${ }^{2}$ Department of Hospital Infections, University Hospital, Oostersingel 59, 9700 RB Groningen,
} The Netherlands

Implanted prostheses or temporary inserted medical devices are frequently associated with infections. Coagulase-negative staphylococci (CNS) are most often isolated from such infections (Garvey, 1980). The adhesion of the CNS onto the surface of the devices has been considered to play an essential role in the initiation of infections (Peters et al., 1982; Sugarman, 1982).

In this study surface characteristics of various strains of CNS such as hydrophobicity, relative negative surface charge and the presence of capsules, were determined. Subsequently, the adhesion of various strains of Staphylococcus epidermidis and S. saprophyticus onto fluorinated polyethylenepropylene (FEP), a hydrophobic biomateral was studied. Since surfaces of devices after contact with blood or body fluids are rapidly coated with a protein layer (Feijen et al., 1979) we also studied the bacterial adhesion onto FEP pre-exposed to plasma.

CNS used in this study were isolated from the skin and from the blood of open heart surgery patients with sepsis or with endocarditis. The strains were classified according to the scheme of Kloos and Schleifer (1975) using the API Staph gallery. In total, 22 strains of S. epidermidis, 21 strains of $S$. saprophyticus, 10 strains of $S$. capitis, 10 strains of $S$. haemolyticus, 8 strains of $S$. hominis, 4 strains of $S$. cohnii and 2 strains of $S$. warneri were identified.

In order to demonstrate the presence of capsules, CNS grown for $20 \mathrm{~h}$ at $37^{\circ} \mathrm{C}$ on sheep blood agar plates were stained using the India ink wet-film method (Duguid, 1951). One strain of S. epidermidis, and 18 S. saprophyticus, 8 S. capitis, 10 S. haemolyticus, 3 S. cohnii and 2 S. warneri strains were encapsulated.

The surface hydrophobicity of CNS was determined by measuring the adherence of late logarithmic-phase bacterial cells to xylene according to Rosenberg et al. (1980) as previously described (Hogt et al., 1983b). CNS showed a wide range in adherence to xylene indicating that the surlace character varied from hydrophilic to hydrophobic. The majority of the strains was rather hydrophobic. No relationship was found between the presence of capsules and surface hydrophobicity.

The relative negative surface charge of CNS was determined by measuring the bacterial adherence to an anion exchange resin according to Pedersen (1981). The relative surface charge of encapsulated CNS was higher than that of the unencapsulated CNS (Fig. 1). Hydrophilic unencapsulated CNS had a rather high relative surface charge. If the strains were less hydrophilic their surface charge decreased. The relative surface charge of hydrophobic CNS widely varied.

The adhesion experiments of S. epidermidis and S. saprophyticus onto FEP films were performed as described previously (Hogt et al., 1983a).

The FEP films were exposed for $1 \mathrm{~h}$ at $37^{\circ} \mathrm{C}$ to PBS or to fresh human plasma and rinsed eight times with PBS avoiding air contact with the films. The films were then exposed for $2.5 \mathrm{~h}$ at $37^{\circ} \mathrm{C}$ 


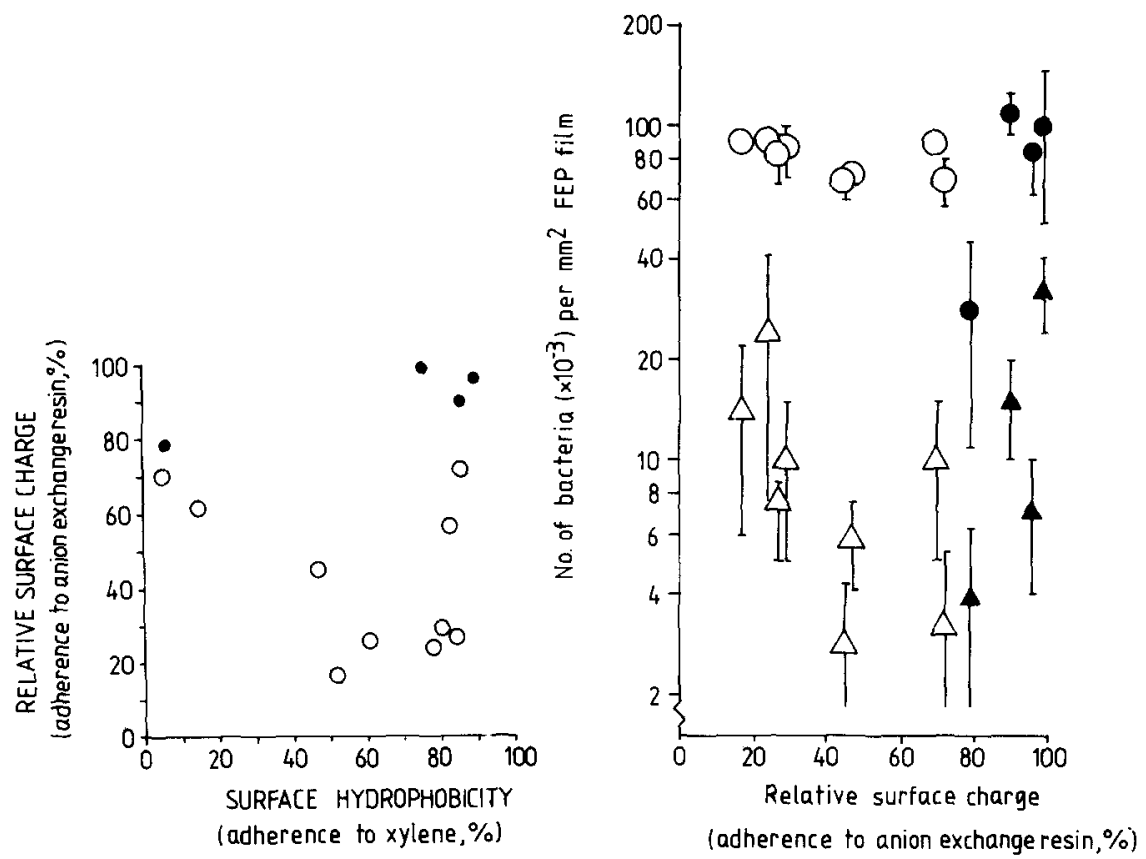

Fig. 1. Relationship between relative surface charge and hydrophobicity of Staphylococcus epidermidis and $S$. saprophyticus strains. $O$, unencapsulated strains; encapsulated strains.

Fig. 2. Adhesion of Staphylococcus epidermidis and S. saprophyticus onto FEP films and FEP films pre-exposed to plasma, as a function of relative bacterial surface charge. $O$, FEP films (control), unencapsulated strains; - FEP films (control), encapsulated strains; $\triangle$, FEP films pre-exposed to plasma, unencapsulated strains; $\boldsymbol{A}$, FEP films pre-exposed to plasma, encapsulated strains.

to washed late logarithmic-phase bacteria suspended in PBS $(0.113 \mathrm{M} \mathrm{NaCl}, 0.01 \mathrm{M}$ phosphate, $\mathrm{pH}$ 7.2) to a concentration of $5 \cdot 10^{8}$ cells per $\mathrm{ml}$ and subsequently rinsed with PBS. The bacteria adhering onto the films were fixed and counted microscopically (six areas of $0.008 \mathrm{~mm}^{2}$ in duplicate experiments).

The adhesion of different unencapsulated strains onto FEP was not related to their hydrophobicity (not shown) nor to their relative surface charge (Fig. 2). This indicates that the bacterial surface hydrophobicity measured in the liquid hydrocarbon adherence assay does not necessarily determine the bacterial ability to adhere to solid polymer surfaces. In an earlier study (Hogt et al., 1983a) we showed by using proteolytic enzyme treatment of CNS, that protein-containing residues at the cell surfaces of CNS are required for the expression of hydrophobic sites which allow the bacteria to adhere to xylene and onto FEP films by hydrophobic bonding. Hydrophilic capsules appeared to inhibit the adhesion onto FEP films.

The number of bacteria adhering onto FEP pre-exposed to plasma was not related to the hydrophobicity of unencapsulated bacteria (not shown). However, it appeared that the adhesion of unencapsulated strains was related to the surface charge. Strains with a high relative (negative) surface charge adhered less to FEP pre-exposed to plasma than strains with a low surface charge (Fig. 2). The results show that adhesion of strains of $S$. epidermidis and $S$. saprophyticus onto FEP films 
pre-exposed to plasma is reduced in comparison to their adhesion onto the control FEP films preexposed to PBS. This may be due to the decrease in hydrophobicity of the FEP films by the absorbed protein layer. In addition, the absorbed protein might cause an electrostatic repulsion between the bacteria and the FEP surface.

This work was supported by a grant from the Netherlands Organization for the Advancement of Pure Research (Z.W.O.).

Duguid, J. P. 1951. The demonstration of bacterial capsules and slime. - J. Pathol. Bacteriol. 63: $673-685$.

Feijen, J., Beugeling, T., Bantjes, A. and Smit-Sibinga, C. TH. 1979. Biomaterials and interfacial phenomena. - Adv. Cardiovasc. Phys. 3: 100-134.

GARVEY, G. 1980. Endovascular and prosthetic implant infections. p. 693-745. In M. H. Grieco (ed.), Infections in the Abnormal Host. - Yorke Medical Books, New York.

Hogt, A. H., Dankert, J., De VRIES, J. A. and FeIJen, J. 1983a. Adhesion of coagulase-negative staphylococci to biomaterials. - J. Gen. Microbiol. 129: 2959-2968.

Hogt, A. H., DANKERT, J. and FeIJEN, J. 1983b. Encapsulation, slime production and surface hydrophobicity of coagulase-negative staphylococci. - FEMS Microbiol. Lett. 18: 211-215.

KLOOS, W. E. and SCHLEIFER, K. H. 1975. Simplified scheme for routine identification of human Staphylococcus species. - J. Clin. Microbiol. 1: 82-88.

Pedersen, K. 1981. Electrostatic interaction chromatography, a method for assaying the relative surface charges of bacteria. - FEMS Microbiol. Lett. 12: 365-367.

Peters, G., LoCCI, R. and Pulverer, G. 1982. Adherence and growth of coagulase-negative staphylococci on surfaces of intravenous catheters. - J. Infect. Dis. 146: 479-482.

RosenberG, M., GUTNICK, D. and Rosenberg, E. 1980. Adherence of bacteria to hydrocarbons: a simple method for measuring cell-surface hydrophobicity. - FEMS Microbiol. Lett. 9: 29-33.

SUGARMAN, B. 1982. In vitro adherence of bacteria to prosthetic vascular grafts. - Infection 10: $9-12$.

\section{Prevention of bacterial endocarditis: exposure to penicillin and the adhesion properties of viridans streptococci onto a fibrin matrix}

\section{J. Dankert, J. Hess, W. Joldersma and J. Woltjes}

\section{Laboratory of Medical Microbiology, Department of Hospital Epidemiology and Department of Pediatric Cardiology, University Hospital, Groningen, The Netherlands}

Viridans streptococci (VS) are mainly the causative organisms of bacterial endocarditis (BE). VS isolated from blood obtained from 15 patients with BE were tested for susceptibility to penicillin (Dankert and Hess, 1982). In total 7 out of the 15 VS revealed to be tolerant to penicillin. Therefore penicillin-tolerant VS caused BE in a significant number of patients. Penicillin-tolerant VS have also been isolated from the gingival sulcus flora of children with cardiac disease prior to penicillin prophylaxis for dental extraction. In total 14 out of 35 children studied proved to have tolerant strains in their gingival sulcus flora.

To assess whether penicillin-tolerant VS had any significance during penicillin prophylaxis, we compared the effect of penicillin prophylaxis to prevent experimentally induced BE in rabbits caused by penicillin-sensitive and penicillin-tolerant VS (Hess et al., 1983). BE developed in only $9 \%$ of the rabbits given penicillin after injection with the penicillin-sensitive strain. BE developed in 27 , 40 and $80 \%$ of the rabbits injected with three tolerant strains, despite penicillin prophylaxis. This meant that a single injection of penicillin failed to prevent BE in rabbits challenged with the tolerant strains. However, no BE developed in a rather high percentage of the rabbits, given the fact that 